\title{
Sequence determinants of the folding properties of box C/D kink-turns in RNA
}

\author{
SAIRA ASHRAF, LIN HUANG, and DAVID M.J. LILLEY \\ Cancer Research UK Nucleic Acid Structure Research Group, MSI/WTB Complex, The University of Dundee, Dundee DD1 5EH, United Kingdom
}

\begin{abstract}
Folding properties differ markedly between kink-turns (k-turns) that have different biological functions. While ribosomal and riboswitch k-turns generally fold into their kinked conformation on addition of metal ions, box C/D snoRNP k-turns remain completely unfolded under these conditions, although they fold on addition of L7Ae protein. Sequence elements have been systematically exchanged between a standard ribosomal k-turn (Kt-7) that folds on addition of metal ions, and a box C/D kturn. Folding was studied using fluorescence resonance energy transfer and gel electrophoresis. Three sequence elements each contribute in an approximately additive manner to the different folding properties of Kt-7 and box C/D k-turns from archaea. Bioinformatic analysis indicates that k-turn sequences evolve sequences that suit their folding properties to their biological function. The majority of ribosomal and riboswitch k-turns have sequences allowing unassisted folding in response to the presence of metal ions. In contrast, box C/D k-turns have sequences that require the binding of proteins to drive folding into the kinked conformation, consistent with their role in the assembly of the box C/D snoRNP apparatus. The rules governing the influence of sequence on folding properties can be applied to other standard k-turns to predict their folding characteristics.
\end{abstract}

Keywords: RNA structure; snoRNP; k-turns; metal ions; L7Ae

\section{INTRODUCTION}

Kink turns (k-turns) are structural elements found in double-stranded RNA (Klein et al. 2001) that can adopt a tightly kinked geometry, mediating long-range tertiary contacts and frequently acting as protein binding sites. k-turns are widespread in functional RNA molecules, including the ribosome, the tri-snRNP spliceosomal complex, snoRNPs, and riboswitches (for review, see Huang and Lilley 2016). The conditions that lead to folding into the kinked conformation differ between different classes of k-turns, in a manner that is evidently related to the biological function of the RNA in which they occur.

The standard k-turn comprises a 3-nucleotide (nt) bulge followed by tandem trans sugar-Hoogsteen $G \cdot A$ and $A \cdot G$ base pairs (Fig. 1). k-turns can fold into a kinked conformation, where the bulge is located at the apex and the axes include an angle of $50^{\circ}$ (Daldrop and Lilley 2013). The nomenclature of the nucleotide positions in the k-turn (Liu and Lilley 2007) is indicated in Figure 1A. The k-turn folds by juxtaposing the minor grooves of the two helical arms, whereupon additional hydrogen bonds form across the interface. The nucleobases of the conserved adenine nucleotides of the $\mathrm{G} \bullet \mathrm{A}$ pairs accept hydrogen bonds from $2^{\prime}$-hydroxyl

Corresponding author: d.m.j.lilley@dundee.ac.uk

Article is online at http://www.rnajournal.org/cgi/doi/10.1261/rna. 063453.117. Freely available online through the RNA Open Access option. groups at the $-1 \mathrm{n}$ and $\mathrm{L} 1$ positions in important, crossstrand interactions (Lescoute et al. 2005; Liu and Lilley 2007; Réblová et al. 2011; Daldrop and Lilley 2013).

Some k-turns fold into the kinked conformation on addition of metal ions (e.g., $\sim 100 \mu \mathrm{M} \mathrm{Mg}^{2+}$ ions), while some do not (McPhee et al. 2014). However, in general most k-turns fold upon binding specific proteins, especially the L7Ae class of RNA binding proteins (Turner et al. 2005; Wang et al. 2012; McPhee et al. 2014). For example, the ribosomal kturn Kt-7 of Haloarcula marismortui adopts the kinked conformation in the presence of $\mathrm{Mg}^{2+}$ ions, whereas the human U4 snRNA k-turn remains unfolded in metal ions and requires the binding of the $15.5 \mathrm{k}$ protein (a member of the L7Ae family [Koonin et al. 1994; Nottrott et al. 1999]) to fold. We have previously shown that the identity of the base pair that follows the distal $A \cdot G$ pair (the $3 b: 3 n$ base pair) determines the difference in folding characteristics between Kt-7 and the U4 k-turn (McPhee et al. 2014).

While the nature of the $3 \mathrm{~b}: 3 \mathrm{n}$ base pair correlated well with the folding characteristics of most k-turns (McPhee et al. 2014), there was one class that did not conform. This is the box C/D snoRNA that binds the L7Ae or $15.5 \mathrm{k}$ protein (in archaea and higher eukaryotes, respectively) as the first stage in the assembly of the box C/D snoRNP that directs the site-

(C) 2017 Ashraf et al. This article, published in $R N A$, is available under a Creative Commons License (Attribution 4.0 International), as described at http://creativecommons.org/licenses/by/4.0/. 
A
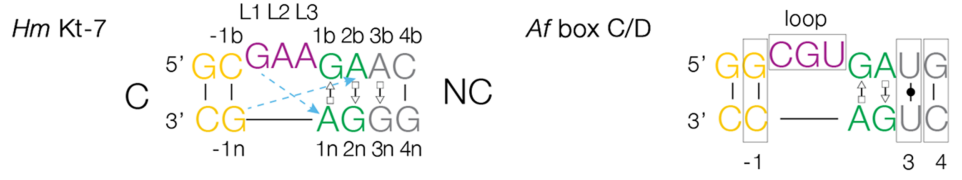

B
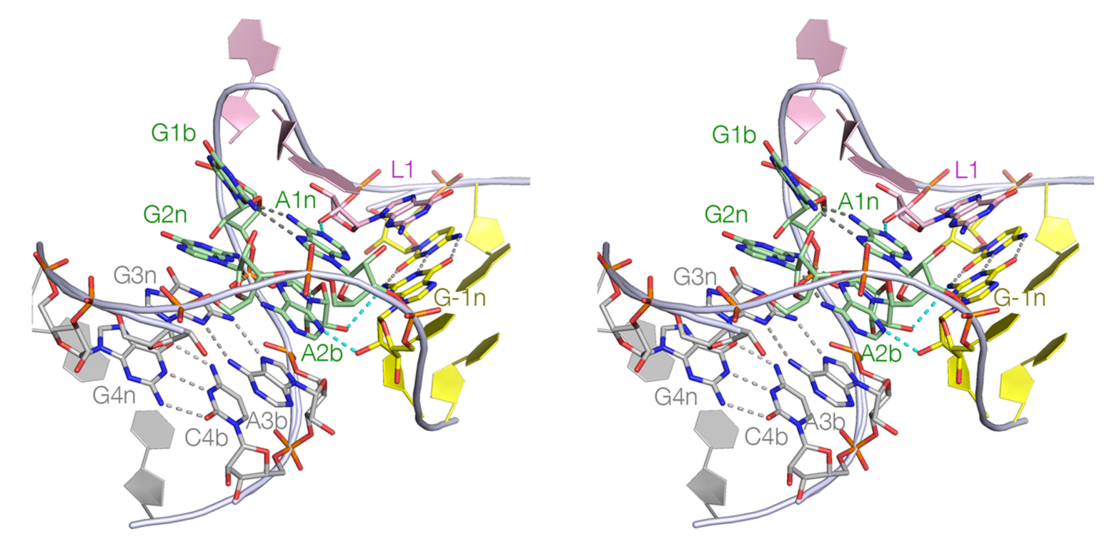

FIGURE 1. The k-turn structure in RNA. (A) The sequences of H. marismortui Kt-7 and A. fulgidus box C/D k-turns. The broken arrows colored in cyan indicate two critical cross-strand hydrogen bonds from the $\mathrm{O}^{\prime}$ of $\mathrm{L} 1$ and $-1 \mathrm{n}$ to the nucleobases of adenines $1 \mathrm{n}$ and $2 \mathrm{~b}$, respectively, that form the trans sugar-Hoogsteen G•A base pairs. The nomenclature of the nucleotide positions is shown on the Kt-7 sequence (left), and the various positions within the k-turn analyzed in this work are boxed on the box C/D sequence (right). In this view, the C-helix is on the left, while the NC-helix (that contains the $\mathrm{G} \cdot \mathrm{A}$ base pairs) is on the right side. (B) Parallel-eye stereoscopic image of the structure of the H. marismortui Kt-7 k-turn observed from the side of the non-bulged strand. The nucleotide positions that are studied and discussed in this work are identified. This image was prepared using PDB ID 4CS1, determined at 2.0 A resolution (McPhee et al. 2014).

specific O2'-methylation of RNA (Kiss-László et al. 1996; Tycowski et al. 1996; Watkins et al. 2000, 2002; Tran et al. 2003; Bleichert et al. 2009; Ye et al. 2009; Xue et al. 2010; Lin et al. 2011). We have observed that the box C/D k-turn of Archaeoglobus fulgidus fails to undergo detectable folding in the presence of $\mathrm{Mg}^{2+}$ ions, studied either by fluorescence resonance energy transfer (FRET; this work) or by X-ray scattering inteferometry (Shi et al. 2016). This was a surprising result, because box $\mathrm{C} / \mathrm{D}$ k-turn has $3 \mathrm{~b}: 3 \mathrm{n}=\mathrm{U}: \mathrm{U}$, and when inserted into Kt-7 U:U at position $3 \mathrm{~b}: 3 \mathrm{n}$ results in a moderate degree of folding in metal ions (McPhee et al. 2014). Therefore, another element within the A. fulgidus box C/D $\mathrm{k}$-turn sequence must influence the ion-dependent folding, completely preventing the folding of the box C/D k-turn.

Comparing the sequences of the H. marismortui Kt-7 and the $A$. fulgidus box C/D k-turns, given the conservation and role of the tandem $\mathrm{G} \cdot \mathrm{A}$ and $\mathrm{A} \cdot \mathrm{G}$ base pairs, the likely elements that might influence the folding properties are the $-1 \mathrm{~b}:-1 \mathrm{n}$, loop, and $4 \mathrm{~b}: 4 \mathrm{n}$ sequence over and above the $3 \mathrm{~b}: 3 \mathrm{n}$ sequence already identified. We have therefore systematically exchanged these four sequence elements between Kt7 and box C/D k-turns, and examined the ion-dependent folding of the hybrid k-turns by FRET. In this study we have only exchanged these elements, not explored the effect of a wider range of substitutions. Yet a clear result emerges from this study that in addition to the influence of the $3 \mathrm{~b}: 3 \mathrm{n}$ position, the $-1 \mathrm{~b}:-1 \mathrm{n}$ and $4 \mathrm{~b}: 4 \mathrm{n}$ sequences also affect the folding properties, of which the $-1 \mathrm{~b}$ : $-1 \mathrm{n}$ position has a particularly strong influence. We show that the distribution of these sequences fit the biological requirements of the different k-turns, in particular differentiating those that are required to fold in metal ions alone from those that will require a bound protein to stabilize the folded geometry.

\section{RESULTS}

\section{A comparative study of two k-turn sequences}

In this work, we have made a systematic comparison of $\mathrm{k}$ turn folding in the presence of $\mathrm{Mg}^{2+}$ ions by H. marismortui bacterial Kt-7 ( $\mathrm{Hm} \mathrm{Kt-7)}$ and the box C/D snoRNA from $A$. fulgidus (Afbox C/D). These differ primarily in the $-1 \mathrm{~b}:-1 \mathrm{n}$, loop, 3b:3n and 4b:4n sequences (Fig. 1). Unless it is explicitly stated otherwise, we shall simply refer to the two k-turns as Kt-7 and box C/D from here on. For these experiments, two series of molecules have been constructed in which the central k-turn is derived either from Kt-7 or box C/D. The sequences have been systematically varied, replacing the $-1 \mathrm{~b}:-1 \mathrm{n}$, loop, $3 \mathrm{~b}: 3 \mathrm{n}$ or $4 \mathrm{~b}: 4 \mathrm{n}$ sequence with those from the other k-turn. The full sequences are presented in Materials and Methods; note that there are a few additional differences between the Kt-7 and box C/D outside the central $\mathrm{k}$-turn region, and the $\mathrm{C}$-helices are not identical in length, so that even when all four elements have been exchanged for a given species the resulting sequence is not identical to the other species. 


\section{Systematic analysis of k-turn folding in $\mathrm{Mg}^{2+}$ ions for Kt-7 and box C/D as a function of sequence}

We have analyzed k-turn folding in response to the addition of $\mathrm{Mg}^{2+}$ ions using a fluorescence resonance energy transfer (FRET) assay. We used k-turn-containing RNA duplex constructs labeled with fluorescein donor and $\mathrm{Cy} 3$ acceptor at the two $5^{\prime}$-termini (Fig. 2). Emission spectra were recorded in the steady state as a function of $\mathrm{Mg}^{2+}$ ion concentration, and the
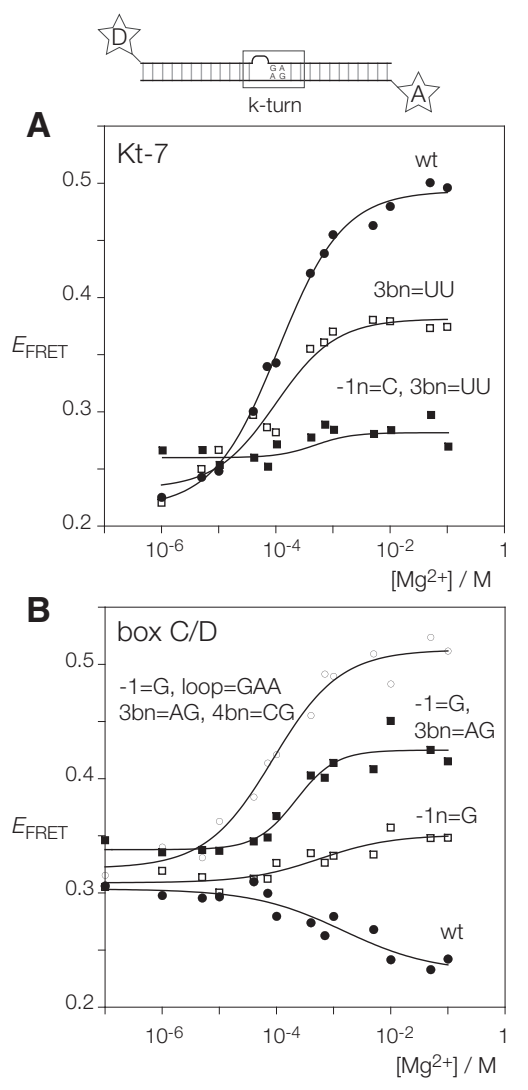

FIGURE 2. Analysis of ion-dependent folding of $H$. marismortui $\mathrm{Kt}-7$ and A. fulgidus box C/D k-turns using FRET. The schematic (top) shows the constructs used in these studies. These are RNA duplexes with a central k-turn sequence, $5^{\prime}$-labeled with fluorescein donor (D) on the bulged strand and $\mathrm{Cy}-3$ acceptor (A) on the nonbulged strand. The sequences are given in Materials and Methods. $E_{\mathrm{FRET}}$ is plotted as a function of $\mathrm{Mg}^{2+}$ ion concentration for both constructs (points), and fitted to the two-state model (line). (A) Titration of $\mathrm{Hm} \mathrm{Kt-7}$ unmodified from the natural sequence (wt, solid circles) and two representative variants in which sequence elements have been exchanged from the box $\mathrm{C} /$ $\mathrm{D}$ k-turn. The single-change variant in which $3 \mathrm{~b}: 3 \mathrm{n}=\mathrm{U}: \mathrm{U}$ (open squares) and the double-change variant with $3 \mathrm{~b}: 3 \mathrm{n}=\mathrm{UU}$ plus $-1 \mathrm{~b}$ : $-1 \mathrm{n}=\mathrm{G}: \mathrm{C}$ (filled squares) are shown. (B) Titration of $A f$ box $\mathrm{C} / \mathrm{D}$ unmodified from the natural sequence (wt, solid circles) and three representative variants in which sequence elements have been exchanged from the $\mathrm{Hm}$ Kt-7 k-turn. The single-change variant in which $-1 \mathrm{~b}$ : $-1 \mathrm{n}=\mathrm{C}: \mathrm{G}$ (open squares), the double-change variant with $-1 \mathrm{~b}:-1 \mathrm{n}$ $=\mathrm{C}: \mathrm{G}$ plus $3 \mathrm{~b}: 3 \mathrm{n}=\mathrm{A}: \mathrm{G}$ (filled squares), and the four-change variant with $-1 \mathrm{~b}:-1 \mathrm{n}=\mathrm{C}: \mathrm{G}, \quad$ loop $=\mathrm{GAA}, \quad 3 \mathrm{~b}: 3 \mathrm{n}=\mathrm{A}: \mathrm{G}$ and $4 \mathrm{~b}: 4 \mathrm{n}=\mathrm{C}: \mathrm{G}$ (open circles) are shown. Note that the four-change variant has effectively converted $A f$ box C/D into $\mathrm{Hm} \mathrm{Kt-7.} \mathrm{Data} \mathrm{from} \mathrm{titration} \mathrm{of} \mathrm{all}$ $\mathrm{Hm} \mathrm{Kt}-7$ and $A f$ box C/D k-turn variants are tabulated in Table 1. efficiency of energy transfer $\left(E_{\mathrm{FRET}}\right)$ calculated using the acceptor normalization procedure (Clegg 1992). If the k-turn adopts the kinked conformation on addition of metal ions or protein binding, the end-to-end distance shortens, and therefore the $E_{\mathrm{FRET}}$ between the terminally attached fluorophores increases. These data have been fitted to a two-state folding model.

Representative titrations are plotted in Figure 2, and the full set of initial and final values of $E_{\mathrm{FRET}}$ are tabulated in Table 1 . In addition, final $E_{\text {FRET }}$ values are plotted in Figure 3. It is readily apparent that the unmodified Kt-7 and box $\mathrm{C} / \mathrm{D}$ sequences respond very differently upon addition of $\mathrm{Mg}^{2+}$ ions. For Kt-7, $E_{\text {FRET }}$ increases over the range, consistent with folding into the k-turn conformation in the presence of the metal ions, and the data are well fitted by the two-state folding model giving a $\left[\mathrm{Mg}^{2+}\right]_{1 / 2}=110 \mu \mathrm{M}$. In contrast, for box C/D the initial value of $E_{\mathrm{FRET}}$ was higher, consistent with a more kinked conformation in the unfolded state, which then decreases on addition of $\mathrm{Mg}^{2+}$ ions. There is no detectable folding of the box C/D construct into the k-turn conformation in response to the addition of metal ions. However, addition of $1 \mu \mathrm{M}$ L7Ae resulted in a final $E_{\text {FRET }}$ of 0.63 , corresponding to complete folding of the k-turn. Thus the box C/D k-turn is capable of adopting the k-turn conformation when bound by L7Ae, despite not being folded by metal ions alone.

The titrations reveal changes of behavior for both species as the key sequence elements are exchanged. For Kt-7, all changes resulted in a reduced extent of k-turn folding, except when the loop was replaced by the box C/D loop CGU when we observed a small increase in the endpoint of $E_{\text {FRET }}$. For box $\mathrm{C} / \mathrm{D}$, introduction of Kt-7 sequence elements tended to result in an increased extent of folding. We discuss the effect of these changes in detail below, but note here that the effects of sequence changes are approximately additive. In some cases we have added $1 \mu \mathrm{M}$ L7Ae following the titration with $\mathrm{Mg}^{2+}$ ions. In all cases this results in an $E_{\mathrm{FRET}}$ of $>0.55$, irrespective of the extent of impairment of folding in $\mathrm{Mg}^{2+}$ ions.

\section{Effect of sequence changes on $\mathrm{Kt}-7$ folding in $\mathrm{Mg}^{2+}$ ions analyzed by gel electrophoresis}

For a subset of the Kt-7 sequences, we have also used gel electrophoresis as an alternative means of studying folding in the presence of $\mathrm{Mg}^{2+}$ ions. These constructs comprised $65 \mathrm{bp}$ DNA/RNA/DNA duplexes with a central core of RNA containing Kt-7 or a modified variant thereof. These were electrophoresed in a $13 \%$ polyacrylamide gel under nondenaturing conditions in recirculated buffer containing $2 \mathrm{mM}$ $\mathrm{MgCl}_{2}$. To provide a reference, a mixture of two equivalent duplexes containing $A_{3}$ and $A_{7}$ bulges in place of k-turns was electrophoresed alongside the Kt-7 samples. The resulting gel (Fig. 4A) shows that the natural-sequence Kt-7 migrates alongside the $A_{7}$ bulge, consistent with the tightly kinked k-turn conformation. However, when the k-turn is 


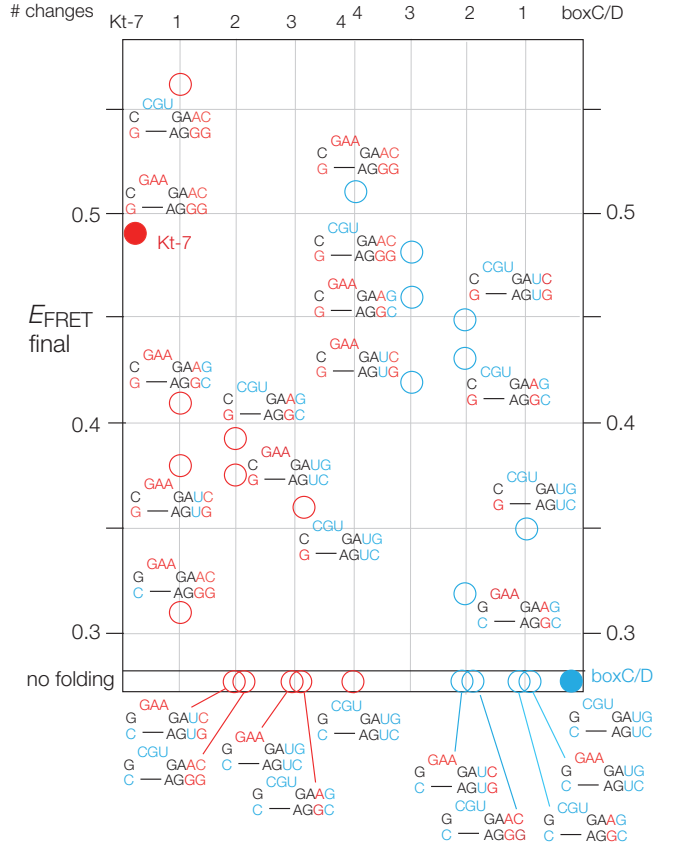

FIGURE 3. FRET analysis of ion-dependent folding of Kt-7 and box C/ $\mathrm{D}$ k-turns and their variants with exchanged sequence elements. Final values of $E_{\mathrm{FRET}}$ in titrations with $\mathrm{Mg}^{2+}$ ions for $\mathrm{Hm} \mathrm{Kt-7}$ and $A f$ box $\mathrm{C} / \mathrm{D}$ k-turns and their variants. Species derived from $\mathrm{Hm} \mathrm{Kt-7}$ are shown in red, and those derived from $A f$ box $\mathrm{C} / \mathrm{D}$ are shown in blue. The unmodified species are shown with filled circles and all the variants with open circles. Those for which no folding was detected by FRET are drawn below the line at the base of the plot. All values of final $E_{\mathrm{FRET}}$ are given in Table 1.

removed by converting all three $A \cdot G$ into $C-G$ base pairs it then migrates with the $\mathrm{A}_{3}$ bulge, i.e., it has a similar degree of bending to a standard 3-nt bulge. Exchanging the $-1 \mathrm{~b}$ : $-1 n$ base pair with or without the loop to their equivalents from box C/D leads to significantly lower electrophoretic retardation, i.e., less kinking in the population, consistent with the FRET results.

\section{$-1 \mathrm{n}$ is a key nucleotide determining the folding characteristics of Kt-7 compared to box C/D k-turns}

The clearest result that emerges from this study is that the major determinant of the difference between the folding properties of Kt-7 and box C/D is the sequence at the $-1 \mathrm{~b}$ : $-1 \mathrm{n}$ position. In $\mathrm{Hm} \mathrm{Kt}-7$ (and indeed in the great majority of k-turns) $-1 \mathrm{~b}:-1 \mathrm{n}$ is $\mathrm{C}: \mathrm{G}$, whereas in the box C/D k-turn it is reversed to $\mathrm{G}: \mathrm{C}$. The $-1 \mathrm{n}$ nucleotide makes a key crossstrand hydrogen bond in the core of the k-turn (see below). Looking at the ensemble of the FRET titration results, for every construct in which $-1 \mathrm{n}=\mathrm{G}$ the final $E_{\mathrm{FRET}}>0.35$. And for every construct in which $-1 \mathrm{n}=\mathrm{C}$, the final $E_{\mathrm{FRET}}<$ 0.32 and does not exhibit detectable folding in $\mathrm{Mg}^{2+}$ ions. Looking at the single changes (i.e., where just one element has been exchanged), the lowest final $E_{\mathrm{FRET}}$ for Kt-7 results from converting $-1 \mathrm{~b}:-1 \mathrm{n}$ to $\mathrm{G}: \mathrm{C}$, and for box $\mathrm{C} / \mathrm{D}$ the only single change that leads to detectable folding is $-1 \mathrm{~b}$ : $-1 n$ changed to C:G. For double and triple changes, the biggest effect results from exchange of the $-1 b:-1 n$ position.

\section{A smaller but generally additive effect of the $3 \mathrm{~b}: 3 \mathrm{n}$ and $4 b: 4 n$ base pairs on k-turn folding}

Bearing in mind that in these experiments we only exchange Kt-7 and box C/D elements, the effects of changes at the $3 \mathrm{~b}: 3 \mathrm{n}$ and $4 \mathrm{~b}: 4 \mathrm{n}$ positions are less marked. The effect of the single change in Kt-7 3b:3n from A: $\mathrm{G}$ to $\mathrm{U}: \mathrm{U}$ is the next largest after the $-1 \mathrm{~b}:-1 \mathrm{n}$ position, and consistent with the identification of $3 b: 3 n=U: U$ as a middle-folding sequence in our earlier systematic study of Kt-7 (McPhee et al. 2014). For double and triple changes, exchanging $3 \mathrm{~b}: 3 \mathrm{n}$ to $\mathrm{U}: \mathrm{U}$ in $\mathrm{Kt}-7$ results in a further reduced final $E_{\text {FRET }}$, while changing $3 \mathrm{~b}: 3 \mathrm{n}$ to $\mathrm{A}: \mathrm{G}$ in box C/D consistently increases $E_{\mathrm{FRET}}$ to a similar degree.

The effect of exchanging the $4 \mathrm{~b}: 4 \mathrm{n}$ sequence is similar in direction and magnitude to the changes at $3 \mathrm{~b}: 3 \mathrm{n}$, and approximately additive with the other changes. In general, changing Kt-7 4b:4n from C:G to G:C leads to lower folding, while the reverse change in box $C / D$ leads to increased folding.

\section{The sequence of the loop influences k-turn folding to a very small degree}

The least important sequence difference between Kt-7 and box C/D for k-turn folding is the loop, which are GAA and $\mathrm{CGU}$, respectively. Making the single change in Kt-7 leads to a small increase in final $E_{\mathrm{FRET}}$, consistent with a small increase in electrophoretic retardation for the same species (Fig. 4), and examples of both loop sequences are found for k-turns folding within the entire range of final $E_{\mathrm{FRET}}$ values. In general, exchange of loop sequences can lead to enhanced or impaired folding for different constructs, and the magnitudes are smaller than any of the other changes explored.

We note that the CGU loop sequence does lead to a higher value of $E_{\text {FRET }}$ for the initial state prior to the addition of metal ions, suggesting that the unfolded k-turns (assumed to behave as simple three-nucleotide bulges) are on average more bent with that loop sequence. That is also supported by a retarded mobility of Kt-7 loop = CGU variant in gel electrophoresis in the absence of $\mathrm{Mg}^{2+}$ ions (Fig. 4B). We have previously noted that the magnitude kinking of base bulges depends on the sequence of the bulge (Bhattacharyya et al. 1990).

\section{Conservation of the $-1 \mathrm{n}$ sequence in k-turns}

The single-most most important sequence difference determining the ion-dependent folding characteristics of Kt-7 and box $\mathrm{C} / \mathrm{D} \mathrm{k}$-turns is the $-1 \mathrm{~b}:-1 \mathrm{n}$ base pair. In the majority of k-turns this is $\mathrm{C}: \mathrm{G}$, but in the $A f$ box C/D k-turn it is 


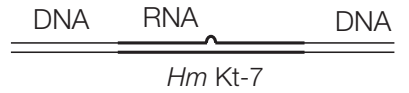

A $2 \mathrm{mM} \mathrm{Mg}^{2+}$
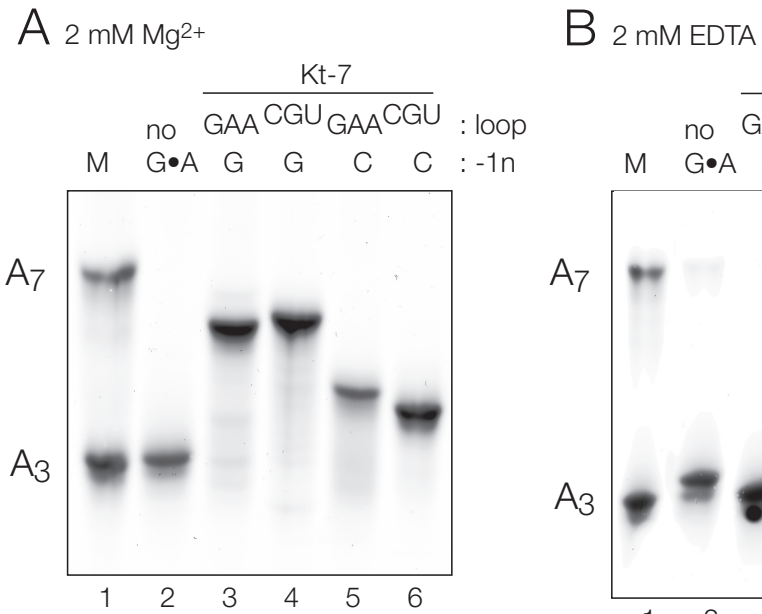
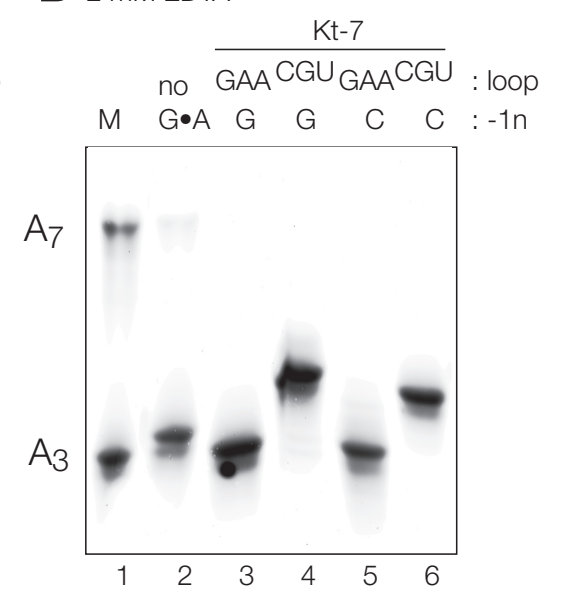

FIGURE 4. Analysis of ion-dependent folding of H. marismortui Kt-7 k-turn using gel electrophoresis. The schematic (top) shows the constructs used in these studies. The k-turn is centrally located in an RNA section embedded within a longer DNA segment giving a total length of $65 \mathrm{bp}$ excluding the bulge. The different species were electrophoresed in a $13 \%$ polyacrylamide gel in the presence of $(A) 2 \mathrm{mM} \mathrm{Mg}^{2+}$ ions or $(B) 2 \mathrm{mM}$ EDTA. To provide a frame of reference, equivalent duplexes in which the k-turn was replaced by an $\mathrm{A}_{3}$ or $\mathrm{A}_{7}$ bulge were mixed and electrophoresed in track 1 . Track 2 contains a Kt-7 variant where the three $\mathrm{G} \cdot \mathrm{A}$ base pairs have been changed to Watson-Crick G-C base pairs by the substitutions of A1n, A2b, and A3b to C. Tracks 3 to 6 contain $\mathrm{Hm} \mathrm{Kt}-7$ variants with various substitutions taken from $A$ f box C/D k-turn. Track 3, unmodified Kt-7; track 4 loop changed to CGU; track 5, $-1 \mathrm{~b}:-1 \mathrm{n}=\mathrm{G}$ :C; track 4, $-1 \mathrm{~b}:-1 \mathrm{n}=\mathrm{G}$ :C plus loop $=$ CGU.

reversed to G:C. We have used bioinformatics to analyze the distribution of k-turn sequences in the two k-turn types studied here. Nucleotide frequency distributions for bacterial Kt7 and archaeal box C/D k-turns are shown in Figure 5 as Web-logo (Crooks et al. 2004) plots. Kt-7 exhibits a strong bias for $-1 \mathrm{~b}:-1 \mathrm{n}=\mathrm{C}: \mathrm{G}$ (Fig. $5 \mathrm{~A}$ ), predisposing the k-turns to ion-dependent folding. Moreover the $3 \mathrm{~b}: 3 \mathrm{n}$ base pair is most frequently $\mathrm{U}: \mathrm{G}$, which we have found to be well folded in $\mathrm{Mg}^{2+}$ ions (McPhee et al. 2014), and the $4 \mathrm{~b}: 4 \mathrm{n}$ base pair is C:G which we show here is also predisposed to ion-dependent folding. So each position in bacterial Kt-7 sequences has evidently evolved to facilitate folding in the presence of $\mathrm{Mg}^{2+}$ ions. More generally, the distribution frequency for $-1 \mathrm{~b}:-1 \mathrm{n}$ has been analyzed for the all the bacterial ribosomal $\mathrm{k}$-turns by Westhof and coworkers (Lescoute et al. 2005), showing $\mathrm{C}: \mathrm{G}=94.3 \% ; \mathrm{G}: \mathrm{C}=3.0 \% ; \quad \mathrm{U}: \mathrm{A}=1.7 \% ; \quad \mathrm{U}: \mathrm{G}=$ $0.8 \%$; and $\mathrm{A}: \mathrm{U}=0.2 \%$. Thus the great majority of sequences should be strongly predisposed to folding in the presence of divalent ions.

The nucleotide frequency distributions for archaeal box C/ D k-turns (Fig. 5B) contrasts significantly with the ribosomal $\mathrm{k}$-turns. The frequencies for the $-1 \mathrm{~b}:-1 \mathrm{n}$ sequences are $\mathrm{C}: \mathrm{G}$ $=39.42 \% ; \mathrm{G}: \mathrm{C}=23.08 \% ; \mathrm{A}: \mathrm{U}=11.54 \% ; \mathrm{U}: \mathrm{U}=7.21 \%$; G:U $=4.33 \%$; and $\mathrm{U}: \mathrm{G}=2.89 \%$. These are more widely distributed, and the second-most frequent $-1 \mathrm{~b}:-1 \mathrm{n}$ sequence is the non-ion-folding G:C. Moreover 3b:3n has a strong propensi-

ty to $\mathrm{U}: \mathrm{U}$, and $4 \mathrm{~b}: 4 \mathrm{n}$ is strongly conserved as G:C. Evidently box C/D sequences have evolved to be unfolded in divalent metal ions, and in general will require protein binding to fold into their kinked conformation.

\section{A role for the exocyclic amine of $\mathrm{G}-1 \mathrm{n}$ in k-turn folding}

We have established that the great majority of k-turns have $-1 \mathrm{~b}:-1 \mathrm{n}=\mathrm{C}: \mathrm{G}$, and that if this base pair is reversed then folding in the presence of $\mathrm{Mg}^{2+}$ ions is severely impaired. The nucleotide at $-1 \mathrm{n}$ makes one of the key cross-strand A-minor interactions in the core of the k-turn (Fig. $6 \mathrm{~A})$. The $\mathrm{O} 2^{\prime}$ donates its proton to the nucleobase of A2b. The acceptor can be either N3 or N1, but in HmKt-7 (except within the ribosome) the proton is accepted by N3 (Daldrop and Lilley 2013). Additionally however, when $-1 \mathrm{n}=\mathrm{G}$, the nucleobase can form a hydrogen bond from $\mathrm{N} 2$ to the $\mathrm{O} 2^{\prime}$ of $\mathrm{A} 2 \mathrm{~b}$. We therefore used atomic mutagenesis to assess the importance of this interaction to the $\mathrm{Mg}^{2+}$ ion-dependent folding of Kt-7. We selectively removed the exocyclic amine of A2b by inosine substitution and studied the folding in response to addition of $\mathrm{Mg}^{2+}$ ions using FRET as before (Fig. 6B). Folding is significantly impaired by removal of the $\mathrm{N} 2$ amine, achieving a final $E_{\mathrm{FRET}}$ of 0.36 . Thus when $-1 \mathrm{~b}$ : $-1 \mathrm{n}=\mathrm{C}: \mathrm{G}$ an additional cross-strand hydrogen bond forms, and this may help to tip the free energetic balance towards folding in the presence of $\mathrm{Mg}^{2+}$ ions.

\section{DISCUSSION}

This study has demonstrated that the ribosomal k-turn $\mathrm{Hm}$ Kt-7 and the $A f$ box C/D snoRNP k-turn have evolved sequences that dictate very different folding properties. By selectively exchanging segments between the two we have found that a number of sequence elements in the standard k-turn determine the folding properties in the presence of divalent metal ions that are suited to their function. These are principally the $-1 \mathrm{~b}:-1 \mathrm{n}, 3 \mathrm{~b}: 3 \mathrm{n}$, and $4 \mathrm{~b}: 4 \mathrm{n}$ base pairs. We had previously established the importance of the $3 \mathrm{~b}: 3 \mathrm{n}$ base pair in determining whether or not a k-turn would fold in response to the presence of metal ions (McPhee et al. 2014), as well as the conformation adopted (Huang et al. 2016). We now find that additional elements can exert a significant influence on the folding properties in an approximately additive manner, particularly the $-1 \mathrm{~b}:-1 \mathrm{n}$ base pair. This generates a set of "rules" relating k-turn sequence to their ability to fold in 
TABLE 1. FRET analysis of ion-dependent folding of Kt-7 and box C/D k-turns and their variants with exchanged sequence elements

\begin{tabular}{|c|c|c|c|c|c|c|c|}
\hline & $-1 n$ & loop & $3 b, 3 n$ & $4 b, 4 n$ & $E_{\text {final }}$ & $E_{\text {initial }}$ & + L7Ae $E_{\text {final }}$ \\
\hline \multirow[t]{5}{*}{ Kt-7 } & G & GAA & AG & CG & 0.49 & 0.21 & 0.63 \\
\hline & $\mathrm{C}$ & & & & 0.31 & 0.14 & \\
\hline & 1 & & & & 0.38 & 0.21 & \\
\hline & & CGU & & & 0.56 & 0.33 & \\
\hline & & & UU & & 0.38 & 0.23 & \\
\hline \multirow[t]{10}{*}{ One change } & & & & GC & 0.41 & 0.14 & \\
\hline & C & CGU & & & NF & & 0.64 \\
\hline & C & & UU & & NF & & 0.62 \\
\hline & $\mathrm{C}$ & & $\mathrm{AC}$ & & $\mathrm{NF}$ & & 0.56 \\
\hline & $\mathrm{C}$ & & & GC & 0.29 & 0.19 & \\
\hline & $\mathrm{C}$ & AAA & & & $\mathrm{NF}$ & & 0.62 \\
\hline & $\mathrm{C}$ & CAA & & & $\mathrm{NF}$ & & 0.60 \\
\hline & & CGU & & GC & 0.39 & 0.25 & \\
\hline & & CGU & UU & & 0.52 & 0.28 & 0.64 \\
\hline & & & UU & GC & 0.32 & 0.22 & \\
\hline \multirow[t]{4}{*}{ Two changes } & I & & UU & & 0.36 & 0.27 & \\
\hline & $\mathrm{C}$ & CGU & & GC & $\mathrm{NF}$ & & \\
\hline & $\mathrm{C}$ & & UU & GC & NF & & \\
\hline & $\mathrm{C}$ & CGU & UG & & 0.43 & 0.28 & \\
\hline Three changes & & CGU & UU & GC & 0.36 & 0.24 & 0.64 \\
\hline Four changes & $\mathrm{C}$ & CGU & UU & GC & $\mathrm{NF}$ & & 0.58 \\
\hline \multirow[t]{2}{*}{ Box C/D } & $\mathrm{C}$ & CGU & UU & GC & $\mathrm{NF}$ & & 0.63 \\
\hline & G & & & & 0.35 & 0.31 & \\
\hline \multirow[t]{2}{*}{ One change } & & GAA & & & $\mathrm{NF}$ & & \\
\hline & & & AG & & NF & & \\
\hline \multirow[t]{6}{*}{ Two changes } & & & & CG & $\mathrm{NF}$ & & \\
\hline & G & GAA & & & 0.30 & 0.29 & \\
\hline & G & & AG & & 0.43 & 0.34 & \\
\hline & G & & & CG & 0.45 & 0.37 & \\
\hline & & GAA & AG & & 0.32 & 0.27 & \\
\hline & & GAA & & CG & $\mathrm{NF}$ & & \\
\hline \multirow[t]{4}{*}{ Three changes } & & & AG & CG & $\mathrm{NF}$ & & \\
\hline & G & GAA & AG & & 0.46 & 0.26 & 0.56 \\
\hline & G & GAA & & CG & 0.42 & 0.36 & \\
\hline & G & & AG & CG & 0.48 & 0.40 & \\
\hline Four changes & G & GAA & AG & CG & 0.51 & 0.32 & 0.61 \\
\hline
\end{tabular}

Tabulation of initial $\left(E_{\text {initial }}\right)$ and final $\left(E_{\text {final }}\right)$ values of $E_{\text {FRET }}$ for k-turns on titration with $\mathrm{Mg}^{2+}$ ions, where $-1 \mathrm{~b}:-1 \mathrm{n}$, loop, $3 \mathrm{~b}: 3 \mathrm{n}$, and $4 \mathrm{~b}: 4 \mathrm{n}$ elements have been exchanged in different combinations. For some of these constructs, L7Ae was added at the end of the $\mathrm{Mg}^{2+}$ ion titration and the final $E_{\text {FRET }}$ reported. Note that although some constructs are the same in terms of the four elements (e.g., the box C/D with four elements changed is effectively Kt-7), small differences in their context (including the length of the C-helix) means they are not identical. NF, no detectable folding.

the presence of $\mathrm{Mg}^{2+}$ ions. Those that cannot do so will require additional assistance to fold into the kinked conformation, most notably the binding of proteins such as members of the L7Ae family. We have observed that each k-turn whose sequence prevents ion-dependent folding will nevertheless fold in response to the binding of L7Ae, including the Af box C/D k-turn. Similarly, we have previously shown that human box C/D k-turns fold on binding the mammalian L7Ae homolog 15.5k protein (Huang et al. 2017).

Every element of the sequence of $\mathrm{Hm} \mathrm{Kt}-7$ predisposes it to fold in response to the presence of $\mathrm{Mg}^{2+}$ ions, with $\mathrm{G}$ at the critical $-1 \mathrm{n}$ and $3 \mathrm{n}$ positions and $4 \mathrm{~b}: 4 \mathrm{n}=\mathrm{C}: \mathrm{G}$. These elements are strongly conserved in all the bacterial Kt-7 sequences, and more generally in ribosomal k-turns. Most of these do bind various proteins within the ribosome, yet clearly they are not required in order to fold the k-turns. More likely the proteins bind after the folded state has been achieved to fix the structure of the assembling ribosome.

In marked contrast, the Af box C/D k-turn has evidently evolved to prevent folding in the absence of protein binding. $3 \mathrm{~b}: 3 \mathrm{n}=\mathrm{U}: \mathrm{U}$ is one of the intermediate ion-induced-folding k-turns (McPhee et al. 2014), and this is coupled with $-1 \mathrm{~b}$ : $-1 \mathrm{n}=4 \mathrm{~b}: 4 \mathrm{n}=\mathrm{G}: \mathrm{C}$, both of which impair folding in metal ions. Many archaeal box C/D k-turns conform to this sequence pattern. Even where $-1 \mathrm{~b}:-1 \mathrm{n}=\mathrm{C}: \mathrm{G}$, the combination of $3 \mathrm{~b}: 3 \mathrm{n}=\mathrm{U}: \mathrm{U}$ and $4 \mathrm{~b}: 4 \mathrm{n}=\mathrm{G}: \mathrm{C}$ results in very impaired ion-induced folding (Table 1). In human box C/ $\mathrm{D}$ sequences, while the $-1 \mathrm{~b}:-1 \mathrm{n}$ is quite variable, $3 \mathrm{~b}: 3 \mathrm{n}=$ 


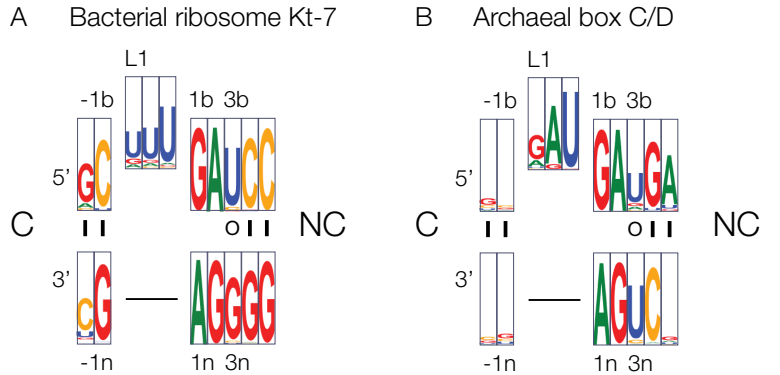

FIGURE 5. Bioinformatic analysis of nucleotide frequencies within bacterial ribosomal Kt-7 and archaeal box C/D k-turns. These data are presented in the form of WebLogo plots (Crooks et al. 2004) where the size of the letters is proportional to the frequency of that nucleotide at a given position. A similar analysis of the human box C/D k-turns made previously is similar to the archaeal plot shown here.

$\mathrm{U}: \mathrm{U}$ and $4 \mathrm{~b}: 4 \mathrm{n}=\mathrm{G}: \mathrm{C}$ are strongly conserved (Huang et al. 2017). In the assembly of the box C/D snoRNP the first event is the binding of L7Ae (15.5k in humans), thereby generating the kinked conformation of the k-turn. This is then followed by the sequential binding of Nop5 (Nop56 plus Nop58 in humans) and finally fibrillarin, the methyl transferase enzyme (Watkins et al. 1998, 2002; Omer et al. 2002; Schultz et al. 2006; McKeegan et al. 2007). However, if the binding of L7Ae/15.5k is prevented, progression to further assembly is blocked (Watkins et al. 2002). Thus assembly of the box C/ $\mathrm{D}$ snoRNP can in principle be controlled at the stage of the binding of L7Ae/15.5k to the k-turn. We have recently shown that in a subset of human box $\mathrm{C} / \mathrm{D}$ sites this can be regulated by $N^{6}$-methylation of Aln, which disrupts the $\mathrm{G} \cdot \mathrm{A}$ trans sugar-Hoogsteen base pair required to form the k-turn (Huang et al. 2017). However, methylation of the Aln requires that the nucleotide at $-1 \mathrm{n}$ be cytosine, to create a GAC target for the METTL3-METTL14 methyl transferase (Dominissini et al. 2012; Meyer et al. 2012) and thus for these box $\mathrm{C} / \mathrm{D}$ species $-1 \mathrm{~b}:-1 \mathrm{n}=\mathrm{G}: \mathrm{C}$.

The occurrence of $-1 \mathrm{~b}:-1 \mathrm{n}=\mathrm{G}: \mathrm{C}$ in the box C/D appears to be largely restricted to this class of k-turn. Indeed, that was the reason the role of this position was not explored earlier. We have previously noted that $98 \%$ of U4 snoRNA k-turns have selected $3 \mathrm{~b}: 3 \mathrm{n}$ sequences that are incompatible with ion-induced folding, yet have $-1 \mathrm{~b}:-1 \mathrm{n}=\mathrm{C}$ :G. Like the box $\mathrm{C} / \mathrm{D} \mathrm{k}$-turns, these will require the binding of $15.5 \mathrm{k}$ protein in the pre-spliceosome to adopt the kinked geometry, but in general have adopted a different sequence strategy to achieve this.

We may ask how the sequence "rules" deduced from the Kt-7 and box C/D sequence exchange experiments apply to another class of k-turns, the riboswitches. Seven different riboswitch types employ k-turns as structural elements. For example, in the SAM-I riboswitch a long helix is kinked by a k-turn so that its terminal loop can make a tertiary interaction to generate the ligand binding site (Montange and Batey 2006). Bioinformatic analysis has shown that in $82 \%$ of the SAM-I k-turns the $3 \mathrm{~b}: 3 \mathrm{n}$ sequences confer ion-induced fold- ing (McPhee et al. 2014), and this is reinforced by the $-1 \mathrm{~b}$ : $-1 \mathrm{n}$ position where $97.7 \%$ have $-1 \mathrm{~b}:-1 \mathrm{n}=\mathrm{C}: \mathrm{G}$ (4757 sequences analyzed). Clearly the SAM-I riboswitch k-turns have a very strong requirement to undergo folding in the presence of metal ions alone, consistent with the absence of known proteins that bind these riboswitches.

In summary, a number of sequence elements in the k-turn contribute to its folding properties, and individual k-turns are adapted to the specific biological requirement. Those that are required to fold in response to metal ions alone will have different sequence elements from those that contribute to the biogenesis of ribonucleoprotein assemblies.

\section{MATERIALS AND METHODS}

\section{RNA synthesis and deprotection}

RNA oligonucleotides were synthesized by solid-phase phosphoramidite chemistry implemented on an ABI-394. The phosphoramidite ribonucleosides, Pac-A-CE, Ac-C-CE, iPr-Pac-G-CE, and U$\mathrm{CE}$, with a $t$-BDMS protecting group on the $2^{\prime} \mathrm{O}$, were obtained from Link Technologies. The I-CE $t$-BDMS phosphoramidite was obtained from Glen Research. Fluorescein (Link Technologies) and $\mathrm{Cy} 3$ (GE Healthcare) were attached to the $5^{\prime}$ termini of the oligonucleotides as phosphoramidites in the final cycle of the

A
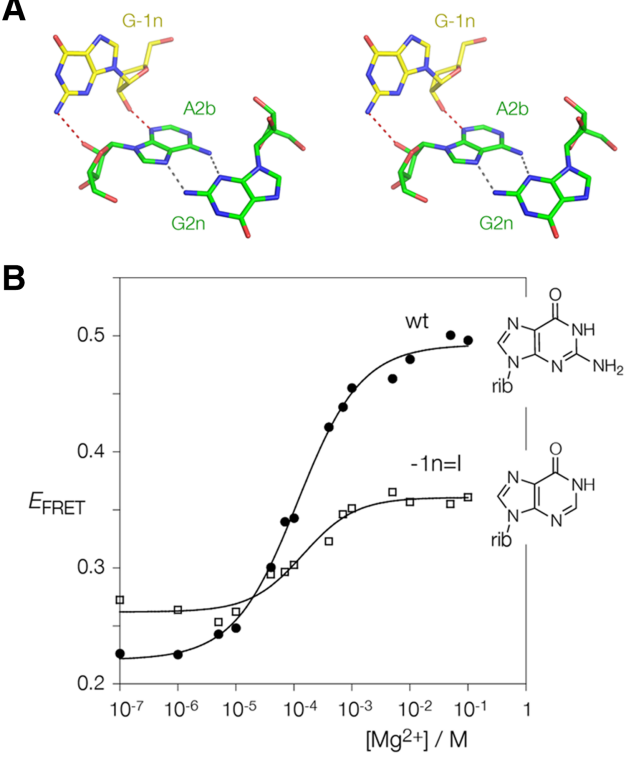

FIGURE 6. Atomic mutagenesis to probe the importance of the hydrogen bonding between G-1n and A2b. (A) Parallel-eye stereoscopic image of the interaction of G-1n with A2b in $\mathrm{Hm}$ Kt-7. The cross-strand hydrogen bonds are colored red. Note the additional hydrogen bond from G-1n N2 to the $\mathrm{O} 2{ }^{\prime}$ of A2b. This image was prepared using PDB ID 4CS1. (B) A modified version of the Kt-7 construct used for FRET analysis was prepared in which G-1n was replaced by inosine, thus replacing the amine at the 2 position with a proton. Folding as a function of $\mathrm{Mg}^{2+}$ ion concentration was studied by measurement of FRET efficiency between the terminally attached fluorophores as before. The data are plotted for unmodified Kt-7 (filled circles) and the G-1nI variant, and fitted to the two-state folding model. Note that the folding of the variant (open squares) lacking the G-1n N2 is significantly impaired. 
synthesis, as required. For comparative gel electrophoretic experiments, DNA-RNA-DNA species were synthesized by incorporating deoxyribonucleosides. $\mathrm{dT}$ and Tac-protected $\mathrm{dA}, \mathrm{dG}$, and $\mathrm{dC}$ were obtained from Sigma-Aldrich.

The oligonucleotides were deprotected in $25 \%$ ethanol/ammonia solution for $3 \mathrm{~h}$ at $20^{\circ} \mathrm{C}$. Fluorophore-labeled oligonucleotides, as well as DNA-RNA-DNA chimeras, were further deprotected for 2 $\mathrm{h}$ at $65^{\circ} \mathrm{C}$. After deprotection, the oligonucleotides were evaporated to dryness. They were redissolved in $115 \mu \mathrm{L}$ DMSO (Sigma-Aldrich) to which was added $60 \mu \mathrm{L}$ triethylamine (TEA) (Sigma-Aldrich) and $75 \mu \mathrm{L} 1 \mathrm{M}$ triethylamine trihydrofluoride (TEA, 3HF) (SigmaAldrich) and incubated at $65^{\circ} \mathrm{C}$ for $2.5 \mathrm{~h}$ to remove the $t$-BDMS protecting groups. Thereafter, the samples were cooled on ice for 10 min and $250 \mu \mathrm{L}$ RNA Quenching Buffer (Glen Research) was added. The oligonucleotides were then desalted by application to NAP-10 columns (GE Healthcare).

\section{RNA purification and hybridization}

The oligonucleotides were purified by gel electrophoresis under denaturing conditions, using 20\% acrylamide: bis-acrylamide (19:1) (Scientific Laboratory Supplies) electrophoresed in $90 \mathrm{mM}$ Tris.borate (pH 8.5), $10 \mathrm{mM}$ EDTA (TBE buffer) containing $7 \mathrm{M}$ urea. Electrophoresis was performed at $25 \mathrm{~W}$ for $\sim 3 \mathrm{~h}$. Nucleic acids were visualized by UV shadowing and bands corresponding to fulllength products were excised and electroeluted into $140 \mu \mathrm{L} 8 \mathrm{M}$ ammonium acetate in $\mathrm{TBE}$ at $150 \mathrm{~V}$ at $20^{\circ} \mathrm{C}$. The nucleic acid was then precipitated with ethanol.

Fluorophore-labeled oligonucleotides were subjected to further purification by reversed-phase HPLC on a C18 column (ACE 10300, Advanced Chromatography Technologies), using an acetonitrile gradient with an aqueous phase of $100 \mathrm{mM}$ triethylammonium acetate ( $\mathrm{pH}$ 7.0) (Fisher Scientific). The samples collected were evaporated to dryness and resuspended in $120 \mu \mathrm{L}$ ultrapure water.

For FRET experiments, equimolar quantities of the appropriate oligonucleotides were annealed in TBE, $25 \mathrm{mM} \mathrm{NaCl}$, and slowly cooled from $95^{\circ} \mathrm{C}$ to $4^{\circ} \mathrm{C}$. Hybridized RNA was purified by gel electrophoresis under nondenaturing conditions in 12\% acrylamide: bis-acrylamide (29:1), in TBE, $25 \mathrm{mM} \mathrm{NaCl}$ with buffer recirculation. Electrophoresis was performed at $150 \mathrm{~V}$ at $4^{\circ} \mathrm{C}$ for $\sim 6$ h. Bands containing duplex RNA were excised from the gel and electroeluted into $140 \mu \mathrm{L} 8 \mathrm{M}$ ammonium acetate in TBE at $100 \mathrm{~V}$ at $4^{\circ}$ $\mathrm{C}$, followed by ethanol precipitation and air-drying at $4^{\circ} \mathrm{C}$.

\section{FRET analysis of k-turn folding}

FRET efficiency was measured from a series RNA duplex species, terminally $5^{\prime}$-labeled with fluorescein on the bulged strand and Cy3 on the nonbulged strand, containing central k-turn sequences and variants (Fig. 2). The unmodified strands were (all sequences written $\left.5^{\prime}-3^{\prime}\right)$ :

\section{Kt-7: Flu-CCAGUCAGUGGCGAAGAACCAUGUCAGG and Cy3-CCUGACAUGGGGAGCCACUGACUGG Box C/D: Flu-CCUCAGUGGGCGUGAUGCAUGUCAUG and Cy3-CAUGACAUGCUGACCCACUGAGG}

Hybridized together these generate $\mathrm{C}$ helices of 12 (Kt-7) and 10 (box C/D) bp, and NC helices of 13 bp (both constructs). Modified versions of these species were constructed as indicated in the text.
Absorption spectra were measured by resuspending the ethanol precipitated hybrid RNA in $120 \mu \mathrm{L} 90 \mathrm{mM}$ Tris-borate ( $\mathrm{pH}$ 8.4) and recording the absorbance in a $50 \mathrm{~mm}$ path length cuvette using a NanoDrop 2000c spectrophotometer (Thermo Scientific). Spectra were deconvoluted using a corresponding RNA species labeled only with $\mathrm{Cy} 3$, and fluorophore absorption ratios calculated using a MATLAB program. Fluorescence spectra were recorded in $90 \mathrm{mM}$ Tris-borate $(\mathrm{pH} 8.4)$ at $4^{\circ} \mathrm{C}$ using an SLM-Aminco 8100 fluorimeter. Spectra were corrected for lamp fluctuations and instrumental variations, and polarization artifacts were avoided by setting excitation and emission polarizers crossed at $54.7^{\circ}$. Values of FRET efficiency were measured using the acceptor normalization method (Clegg 1992) implemented in MATLAB. $E_{\mathrm{FRET}}$ as a function of $\mathrm{Mg}^{2+}$ ion concentration was analyzed on the basis of a model in which the fraction of folded molecules corresponds to a simple two-state process for ion-induced folding, i.e.,

$$
E_{\mathrm{FRET}}=E_{0}+\Delta E_{\mathrm{FRET}} K_{A}\left[\mathrm{Mg}^{2+}\right]^{n} /\left(1+K_{A}\left[\mathrm{Mg}^{2+}\right]^{n}\right),
$$

where $E_{0}$ is the FRET efficiency of the RNA in the absence of added metal ions, $\Delta E_{\mathrm{FRET}}$ is the increase in FRET efficiency at saturating metal ion concentration, $\left[\mathrm{Mg}^{2+}\right]$ is the prevailing $\mathrm{Mg}^{2+}$ ion concentration, $K_{A}$ is the apparent association constant for metal ion binding, and $n$ is a Hill coefficient. Data were fitted to this equation by nonlinear regression. The metal ion concentration at which the transition is half complete is given by $\left[\mathrm{Mg}^{2+}\right]_{1 / 2}=\left(1 / K_{A}\right)^{1 / n}$.

\section{Gel electrophoretic analysis of k-turn folding}

DNA-RNA-DNA duplex species were prepared by annealing equimolar quantities of the appropriate oligonucleotides in $50 \mathrm{mM}$ Tris$\mathrm{HCl}\left(\mathrm{pH} 8.1\right.$ ), and slow cooling from $95^{\circ} \mathrm{C}$ to $4^{\circ} \mathrm{C}$. The hybridized species were then electrophoresed in 13\% acrylamide: bis-acrylamide (29:1) gels in $90 \mathrm{mM}$ Tris-borate ( $\mathrm{pH} 8.3$ ) (TB buffer), $2 \mathrm{mM}$ $\mathrm{MgCl}_{2}$ with buffer recirculation at $>1 \mathrm{~L} \mathrm{~h}^{-1}$. Electrophoresis was performed at $120 \mathrm{~V}$ at $4^{\circ} \mathrm{C}$ for $\geq 72 \mathrm{~h}$. Gels were stained using SYBR Gold (Life Technologies), washed in MilliQ water, and visualized on a Typhoon FLA 9500 (GE Healthcare).

The sequences used for the electrophoretic experiments are shown below.

Kt-7 upper strand:

CGCAAGCGACAGGAACCTCGCCAGUCAGUGGCGAAGAA CCAUGUCAGGGGACTGTCAAGTTGAACAGG

Kt-7 lower strand:

CCTGTTCAACTTGACAGTCCCCUGACAUGGGGAGCCAC UGACUGGCGAGGTTCCTGTCGCTTGCG

The DNA sections of these oligonucleotides are shown underlined. Nucleotide substitutions were introduced into the RNA sections as indicated in the text.

\section{Bioinformatic analysis}

Archaeal box C/D sequences were taken from the box C/D snoRNA Database (http://lowelab.ucsc.edu/snoRNAdb/Annotations-archaea .html) (Omer et al. 2000). The k-turn region was aligned manually based on the known pattern of conserved nucleotides. A WebLogo plot (Crooks et al. 2004) showing the occurrence of box C/D sequences in archaea snoRNA was made using the website http:// weblogo.threeplusone.com. 
Bacterial Kt-7 sequences were taken from the Comparative RNA website (Cannone et al. 2002). Specific k-turn regions were aligned manually using Jalview 2.9 (Waterhouse et al. 2009). This resulted in the analysis 2812 of Kt-7 sequences.

SAM-I riboswitch sequences were taken from the Rfam database (Burge et al. 2013).

All sequence composition and covariation analysis was calculated using a modified version of Jalview 2.9 (Waterhouse et al. 2009), that was kindly provided by Dr. James Procter (University of Dundee).

\section{ACKNOWLEDGMENTS}

We thank our colleague Dr. Tim Wilson for discussion and Cancer Research UK for financial support (program grant A18604).

Received August 10, 2017; accepted September 15, 2017.

\section{REFERENCES}

Bhattacharyya A, Murchie AIH, Lilley DMJ. 1990. RNA bulges and the helical periodicity of double-stranded RNA. Nature 343: 484487.

Bleichert F, Gagnon KT, Brown BA II, Maxwell ES, Leschziner AE, Unger VM, Baserga SJ. 2009. A dimeric structure for archaeal box C/D small ribonucleoproteins. Science 325: 1384-1387.

Burge SW, Daub J, Eberhardt R, Tate J, Barquist L, Nawrocki EP, Eddy SR, Gardner PP, Bateman A. 2013. Rfam 11.0: 10 years of RNA families. Nucleic Acids Res 41: D226-D232.

Cannone JJ, Subramanian S, Schnare MN, Collett JR, D'Souza LM, Du Y, Feng B, Lin N, Madabusi LV, Muller KM, et al. 2002. The comparative RNA web (CRW) site: an online database of comparative sequence and structure information for ribosomal, intron, and other RNAs. BMC Bioinformatics 3: 2 .

Clegg RM. 1992. Fluorescence resonance energy transfer and nucleic acids. Methods Enzymol 211: 353-388.

Crooks GE, Hon G, Chandonia JM, Brenner SE. 2004. WebLogo: a sequence logo generator. Genome Res 14: 1188-1190.

Daldrop P, Lilley DMJ. 2013. The plasticity of a structural motif in RNA: structural polymorphism of a kink turn as a function of its environment. RNA 19: 357-364.

Dominissini D, Moshitch-Moshkovitz S, Schwartz S, Salmon-Divon M, Ungar L, Osenberg S, Cesarkas K, Jacob-Hirsch J, Amariglio N, Kupiec M, et al. 2012. Topology of the human and mouse $\mathrm{m}^{6} \mathrm{~A}$ RNA methylomes revealed by m ${ }^{6} \mathrm{~A}$-seq. Nature 485: 201-206.

Huang L, Lilley DMJ. 2016. The kink turn, a key architectural element in RNA structure. J Mol Biol 428: 790-801.

Huang L, Wang J, Lilley DMJ. 2016. A critical base pair in k-turns determines the conformational class adopted, and correlates with biological function. Nucleic Acids Res 44: 5390-5398.

Huang L, Ashraf S, Wang J, Lilley DM. 2017. Control of box C/D snoRNP assembly by $\mathrm{N}^{6}$-methylation of adenine. EMBO Rep 18: 1631-1645.

Kiss-László Z, Henry Y, Bachellerie JP, Caizergues-Ferrer M, Kiss T. 1996. Site-specific ribose methylation of preribosomal RNA: a novel function for small nucleolar RNAs. Cell 85: 1077-1088.

Klein DJ, Schmeing TM, Moore PB, Steitz TA. 2001. The kink-turn: a new RNA secondary structure motif. EMBO J 20: 4214-4221.

Koonin EV, Bork P, Sander C. 1994. A novel RNA-binding motif in omnipotent suppressors of translation termination, ribosomal proteins and a ribosome modification enzyme? Nucleic Acids Res 22: $2166-2167$.

Lescoute A, Leontis NB, Massire C, Westhof E. 2005. Recurrent structural RNA motifs, isostericity matrices and sequence alignments. Nucleic Acids Res 33: 2395-2409.
Lin J, Lai S, Jia R, Xu A, Zhang L, Lu J, Ye K. 2011. Structural basis for site-specific ribose methylation by box C/D RNA protein complexes. Nature 469: 559-563.

Liu J, Lilley DMJ. 2007. The role of specific 2'-hydroxyl groups in the stabilization of the folded conformation of kink-turn RNA. RNA 13: $200-210$.

McKeegan KS, Debieux CM, Boulon S, Bertrand E, Watkins NJ. 2007. A dynamic scaffold of pre-snoRNP factors facilitates human box C/D snoRNP assembly. Mol Cell Biol 27: 6782-6793.

McPhee SA, Huang L, Lilley DMJ. 2014. A critical base pair in k-turns that confers folding characteristics and correlates with biological function. Nat Commun 5: 5127.

Meyer KD, Saletore Y, Zumbo P, Elemento O, Mason CE, Jaffrey SR. 2012. Comprehensive analysis of mRNA methylation reveals enrichment in 3' UTRs and near stop codons. Cell 149: 1635-1646.

Montange RK, Batey RT. 2006. Structure of the S-adenosylmethionine riboswitch regulatory mRNA element. Nature 441: 1172-1175.

Nottrott S, Hartmuth K, Fabrizio P, Urlaub H, Vidovic I, Ficner R, Lührmann R. 1999. Functional interaction of a novel 15.5kD [U4/ U6.U5] tri-snRNP protein with the $5^{\prime}$ stem-loop of U4 snRNA. EMBO J 18: 6119-6133.

Omer AD, Lowe TM, Russell AG, Ebhardt H, Eddy SR, Dennis PP. 2000. Homologs of small nucleolar RNAs in Archaea. Science 288: 517-522.

Omer AD, Ziesche S, Ebhardt H, Dennis PP. 2002. In vitro reconstitution and activity of a C/D box methylation guide ribonucleoprotein complex. Proc Natl Acad Sci 99: 5289-5294.

Réblová K, Šponer JE, Špačková N, Beššeová I, Šponer J. 2011. A-minor tertiary interactions in RNA kink-turns. Molecular dynamics and quantum chemical analysis. J Phys Chem B 115: 13897-13910.

Schultz A, Nottrott S, Watkins NJ, Lührmann R. 2006. Protein-protein and protein-RNA contacts both contribute to the $15.5 \mathrm{~K}$-mediated assembly of the U4/U6 snRNP and the box C/D snoRNPs. Mol Cell Biol 26: 5146-5154.

Shi X, Huang L, Lilley DMJ, Harbury PB, Herschlag D. 2016. The solution structural ensembles of RNA kink-turn motifs and their protein complexes. Nat Chem Biol 12: 146-152.

Tran EJ, Zhang X, Maxwell ES. 2003. Efficient RNA 2'-O-methylation requires juxtaposed and symmetrically assembled archaeal box C/ D and $C^{\prime} / \mathrm{D}^{\prime}$ RNPs. EMBO J 22: 3930-3940.

Turner B, Melcher SE, Wilson TJ, Norman DG, Lilley DMJ. 2005. Induced fit of RNA on binding the L7Ae protein to the kink-turn motif. RNA 11: 1192-1200.

Tycowski KT, Smith CM, Shu MD, Steitz JA. 1996. A small nucleolar RNA requirement for site-specific ribose methylation of rRNA in Xenopus. Proc Natl Acad Sci 93: 14480-14485.

Wang J, Fessl T, Schroeder KT, Ouellet J, Liu Y, Freeman AD, Lilley DMJ. 2012. Single-molecule observation of the induction of k-turn RNA structure on binding L7Ae protein. Biophys J 103: 2541-2548.

Waterhouse AM, Procter JB, Martin DMA, Clamp M, Barton GJ. 2009. Jalview Version 2 - a multiple sequence alignment editor and analysis workbench. Bioinformatics 25: 1189-1191.

Watkins NJ, Newman DR, Kuhn JF, Maxwell ES. 1998. In vitro assembly of the mouse U14 snoRNP core complex and identification of a 65$\mathrm{kDa}$ box C/D-binding protein. RNA 4: 582-593.

Watkins NJ, Ségault V, Charpentier B, Nottrott S, Fabrizio P, Bachi A, Wilm M, Rosbash M, Branlant C, Lührmann R. 2000. A common core RNP structure shared between the small nucleolar box C/D RNPs and the spliceosomal U4 snRNP. Cell 103: 457-466.

Watkins NJ, Dickmanns A, Lührmann R. 2002. Conserved stem II of the box C/D motif is essential for nucleolar localization and is required, along with the $15.5 \mathrm{~K}$ protein, for the hierarchical assembly of the box C/D snoRNP. Mol Cell Biol 22: 8342-8352.

Xue S, Wang R, Yang F, Terns RM, Terns MP, Zhang X, Maxwell ES, Li H. 2010. Structural basis for substrate placement by an archaeal box C/D ribonucleoprotein particle. Mol Cell 39: 939-949.

Ye K, Jia R, Lin J, Ju M, Peng J, Xu A, Zhang L. 2009. Structural organization of box C/D RNA-guided RNA methyltransferase. Proc Natl Acad Sci 106: 13808-13813. 

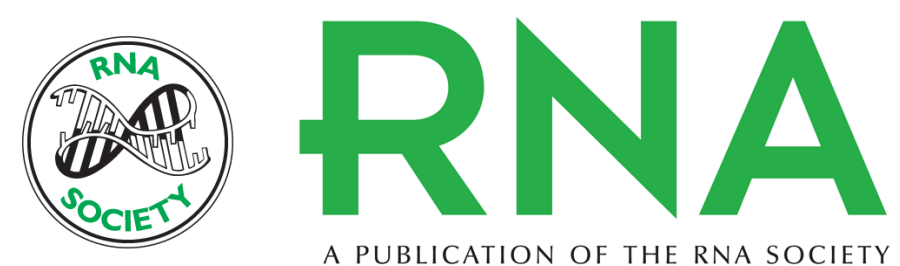

A PUBLICATION OF THE RNA SOCIETY

\section{Sequence determinants of the folding properties of box C/D kink-turns in RNA}

Saira Ashraf, Lin Huang and David M.J. Lilley

RNA 2017 23: 1927-1935 originally published online September 27, 2017

Access the most recent version at doi:10.1261/rna.063453.117

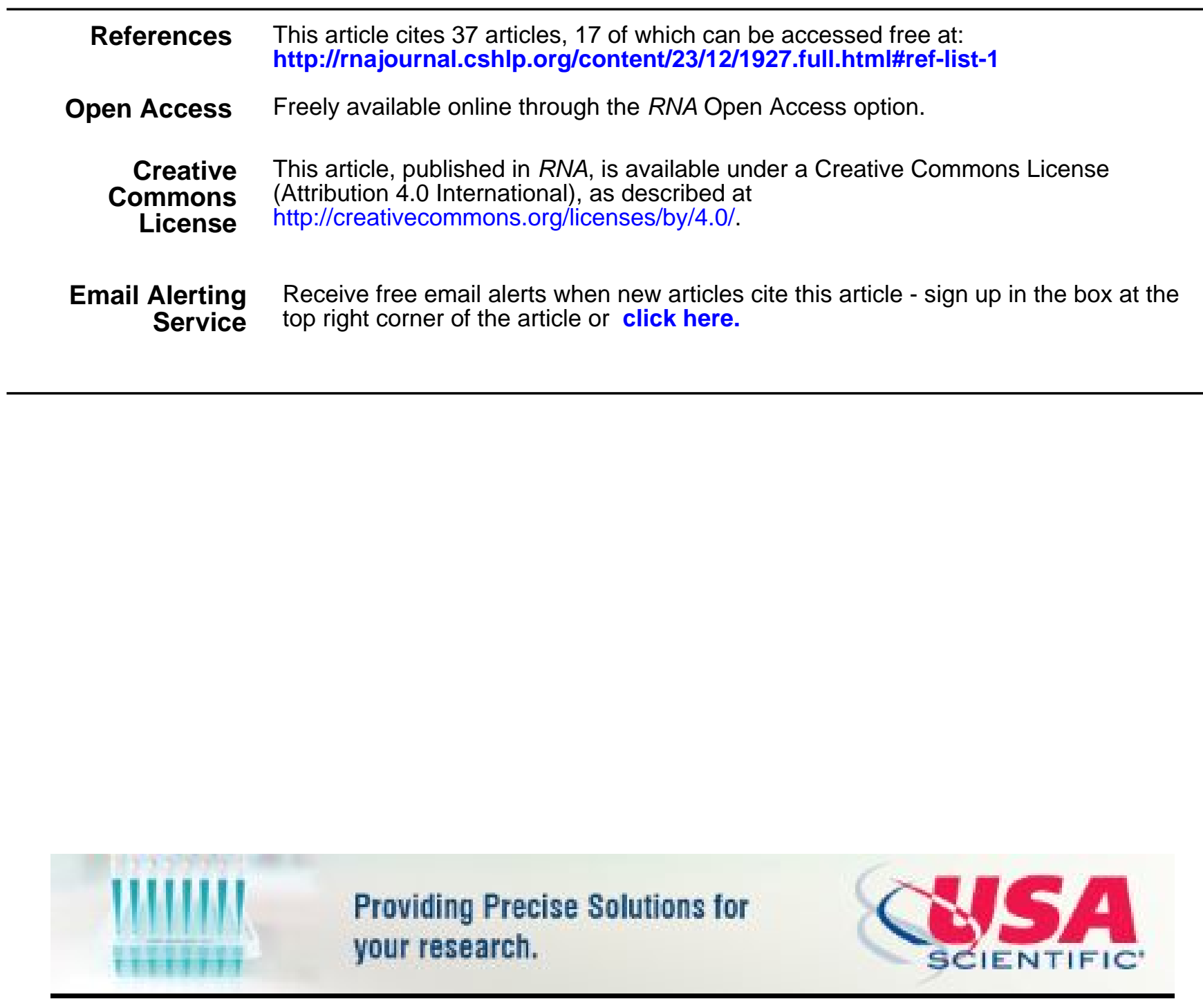

To subscribe to $R N A$ go to:

http://rnajournal.cshlp.org/subscriptions

(C) 2017 Ashraf et al.; Published by Cold Spring Harbor Laboratory Press for the RNA Society 